\title{
Analysis of warm season thunderstorms using an object-oriented tracking method based on radar and total lightning data
}

\author{
T. Rigo, N. Pineda, and J. Bech \\ Meteorological Service of Catalonia, Barcelona, Spain
}

Received: 29 March 2010 - Revised: 29 July 2010 - Accepted: 5 August 2010 - Published: 8 September 2010

\begin{abstract}
Monitoring thunderstorms activity is an essential part of operational weather surveillance given their potential hazards, including lightning, hail, heavy rainfall, strong winds or even tornadoes. This study has two main objectives: firstly, the description of a methodology, based on radar and total lightning data to characterise thunderstorms in real-time; secondly, the application of this methodology to 66 thunderstorms that affected Catalonia (NE Spain) in the summer of 2006. An object-oriented tracking procedure is employed, where different observation data types generate four different types of objects (radar 1-km CAPPI reflectivity composites, radar reflectivity volumetric data, cloud-toground lightning data and intra-cloud lightning data). In the framework proposed, these objects are the building blocks of a higher level object, the thunderstorm.

The methodology is demonstrated with a dataset of thunderstorms whose main characteristics, along the complete life cycle of the convective structures (development, maturity and dissipation), are described statistically. The development and dissipation stages present similar durations in most cases examined. On the contrary, the duration of the maturity phase is much more variable and related to the thunderstorm intensity, defined here in terms of lightning flash rate. Most of the activity of IC and CG flashes is registered in the maturity stage. In the development stage little CG flashes are observed ( $2 \%$ to $5 \%$ ), while for the dissipation phase is possible to observe a few more CG flashes (10\% to $15 \%$ ). Additionally, a selection of thunderstorms is used to examine general life cycle patterns, obtained from the analysis of normalized (with respect to thunderstorm total duration and maximum value
\end{abstract}

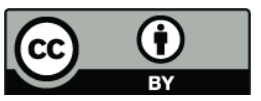

Correspondence to: T. Rigo

(tomeur@meteo.cat) of variables considered) thunderstorm parameters. Among other findings, the study indicates that the normalized duration of the three stages of thunderstorm life cycle is similar in most thunderstorms, with the longest duration corresponding to the maturity stage (approximately $80 \%$ of the total time).

\section{Introduction}

Heavy rainfall and subsequent flash floods produce important damage in the Western Mediterranean and, particularly, in Catalonia (NE Spain). In this region, these events are generally produced in late summer and autumn (Llasat, 2001; Jansá et al., 2001; Martín et al., 2001, 2005; Barnolas and Llasat, 2007; Bech et al., 2007b). These episodes of elevated rain rates, where precipitation is highly efficient, are generally brief and locally focused, and may present high lightning flash rates and severe weather phenomena (Doswell et al., 1996; Pascual, 1999).

Current operational Numerical Weather Prediction (NWP) models have generally difficulties in forecasting correctly the region and the time where heavy rainfall will be produced. The main reasons for this are the model physics and the spatial resolution of the simulations, not precise enough for modelling accurately the behaviour of precipitation convective structures, particularly at high spatial resolution and short time ranges (Creutin et al., 2009; Thielen et al., 2009). Moreover, complex topography and sea-land interactions taking place in Catalonia introduce additional difficulties to forecast correctly these events (Sairouni et al., 2007). Assimilation of radar and satellite data in NWP models has improved the forecasts of heavy rainfall cases (Keenan et al., 2003). However, NWP do not provide satisfactory veryshort term forecasts (less than two hours) of the evolution

Published by Copernicus Publications on behalf of the European Geosciences Union. 
of convective precipitation. In this way, the Meteorological Service of Catalonia (hereafter, SMC) is working in the development of a nowcasting tool based on lightning and 3-D radar data, to help the forecasters in weather surveillance of convective precipitation events.

Considering the organization and internal dynamics of thunderstorms, based in radar data, they can be classified as (Doswell et al., 1996; Rigo and Llasat, 2004): isolated cell (one unique reflectivity core), multicellular (different cells simultaneous or not), or supercell (one unique but stronger than the isolated cell exhibiting a rotating mesocyclone).

The present work has two main objectives. Firstly, the development of a tool which allows integrating in real-time radar and lightning data, giving information and characteristics of thunderstorms, and using these features, to provide the stage of the thunderstorm at a given moment. Secondly, the application of the tool developed to examine 66 thunderstorms that affected Catalonia, in order to obtain a model of behaviour of different lightning and radar parameters. For the sake of simplicity, only isolated cells and multicells with no simultaneous updrafts (a single reflectivity core at a given time) are considered in this work.

The present paper is divided into the following sections: firstly, the different types of detectors, networks, data, and products used are presented; next, the methodology developed and used in this study is commented; the third section shows the results obtained; and, finally, conclusions and future work are outlined.

\section{Background}

One of the most common procedures used for nowcasting precipitating structures is based in tracking the position of the storm centroid (Pierce et al., 2004). In this way, the understanding and use of a life cycle model of thunderstorms, and also the inclusion of lightning data, are necessary in order to improve the short-term forecasting. However, it is essential to have in mind the bonds between radar and lightning data during the different stages of the thunderstorm. This section briefly presents the background information considered in the methodology developed and applied in subsequent sections.

\subsection{Thunderstorm life cycle}

A simplified scheme of the life cycle of a thunderstorm from the point of view of the weather radar and lightning activity can be divided into three main stages (Williams et al., 1989; MacGorman et al., 1989; Doswell, 2001):

- Development: updraft is the predominant motion in this initial stage, allowing the growth of the water particles and the separation of electric charges. First precipitation echoes are observed by the radar and also the first intraclouds flashes (IC) are detected.
- Maturity: this stage is characterised by equilibrium between downdraft and updraft flows; maximum intensity of radar reflectivity echoes are observed at low levels and first cloud-to-ground flashes (CG) are observed. Moreover, during the maturity the maximum lightning activity is observed.

- Dissipation: downdraft is the predominant flow. Radar reflectivity values and lightning activity decrease gradually.

\subsection{Thunderstorm lightning activity}

Lightning activity in thunderstorms has been studied and described in a number of previous studies. The magnitude of the electric field tends to increase inside thunderstorms as the storm height increases. Lightning occurs only when the electric field inside the cloud becomes high enough, after liquid precipitation and graupel are formed (MacGorman and Rust, 1998; Williams, 2001). This can be related with the non-inductive charging (NIC) mechanism, which is likely the most relevant charge separation process for convective storms (Dotzek and Price, 2009). As a result of the NIC mechanism, two dominant charge regions are formed on the main updraft region, one between $-10^{\circ} \mathrm{C}$ and $-20^{\circ} \mathrm{C}$ (usually negative) and a second one higher up, close to $-40^{\circ} \mathrm{C}$ temperature level (usually positive). Several studies have related lightning initiation and intensity to weather radar observations. The moment of lightning initiation has been associated with the presence of a certain threshold of radar reflectivity at a given height (MacGorman and Rust, 1998). On the other hand, the lightning flash rate has been related to the radar echo tops (Williams, 2001) as well as to the extent of high reflectivity at the heights where the negative charge centre is located (MacGorman et al., 1989). Buechler and Goodman (1990) suggested a simple algorithm for storm identification based on reflectivity above $40 \mathrm{dBZ}$ at a $-10^{\circ} \mathrm{C}$ level, which can be obtained from a nearby sounding.

In the present study, vertical temperature profiles obtained from radiosonde data were used to infer the temperatures attained by the radar echo top measurements at the moment of cloud lightning initiation.

\subsection{Relationship between lightning and radar observations}

Lightning activity and convective precipitation are two related characteristics of thunderstorms, as the electrical development is associated with the precipitation formation processes in the cloud (Soula, 2009). This relationship has been studied in different regions, where numerous works have demonstrated good correlations between rainfall and lightning activity (i.e. Williams et al., 1989; Carey and Rutledge, 1996). Pineda et al. (2007) and Pineda and Montanyà (2009) have analysed, in the region of the present study, the relationship between lightning and convective precipitation by 
means of the quantitative estimation of precipitation (QPE), obtained from radar reflectivity (Trapero et al., 2009). Results from these two studies show a good correlation between the daily amount of convective rainfall volume and CG flash counts.

However, the relation between lightning and rainfall is characterised by a certain variability, depending on the geographical features, the season of the year, the type of thunderstorm, and even the stage of the life cycle where the thunderstorm is observed at a given moment (Rakov and Uman, 2003). Moreover, there exist some situations in which there is no apparent relationship, as in dry thunderstorms or in clouds with a high precipitation efficiency and almost nonelectrical activity (Zipser and Lutz, 1994; Petersen et al., 1996).

\subsection{Tracking algorithms}

In the last two decades many tracking and nowcasting algorithms have been developed using mainly radar data. Probably, the most known are TITAN (Dixon and Wiener, 1993) and SCIT (Johnson et al., 1998). TITAN (acronym of Thunderstorm Identification, Tracking, Analysis and Nowcasting) tries to track the whole area of reflectivity echoes, considering a reflectivity threshold as a limiter of the tracked region and measuring distances between centroids as the method to obtain the tracking motion; on the other hand, SCIT (Storm Cell Identification and Tracking algorithm) is a tracker of the centroid of the maximum reflectivity areas. In the same way the first attempts to combine a centroid tracker algorithm with lightning data were done by Goodman (1990). Most of those methodologies were tested during the Olympic Games of Sydney 2000, in the mark of the Forecast Demonstration Project (Wilson et al., 2004).

In the last years, new procedures have been developed, adapted or improved in order to help forecasters in the shorttime predictions. In this sense, TRACE3-D (Handwerker, 2002) and TRT (Thunderstorms Radar Tracking; Hering et al., 2007) are essentially modifications of SCIT, working as operative nowcasting systems at the German and Swiss meteorological services.

Contrary to this centroid position tracking algorithms, other methodologies consider the whole radar reflectivity field, sometimes decomposed with some scaling method, and apply cross correlation techniques to compute a vector field displacement. This is the case of the TREC (Rinehart and Garvey, 1978) and COTREC systems and the last version, CELLTRACK (Kyznarová and Novák, 2008), used in the Czech Hydrometeorological Institute. Other nowcasting systems, are based on the derivation of the whole motion field by means of spectral analysis of the radar reflectivity image (Seed, 2003; Xu and Chandrasekhar, 2005).

Most of these techniques automatically use radar echoes features (position, reflectivity, TOP, velocity...) in order to generate short-time forecasts (up to $1 \mathrm{~h}$ ) and to analyse the life cycle of the storms, considering object-oriented techniques with or without lightning data (Rigo et al., 2005; Brovelli et al., 2005; Hand and Conway, 1996; Soul et al., 2002). In this way, strong relationships between lightning and radar characteristics have been observed (Williams et al., 1989), and they have been used for the development, in operative terms, of methods which combines one of the previous techniques with lightning flashes observations (Bonelli and Marcacci, 2008). Other studies such as Medaglia et al. (2005) use satellite and lightning observations for thunderstorm tracking procedures.

\section{Data used}

\subsection{Radar data}

The Weather Radar Network (XRAD) of the Meteorological Service of Catalonia (SMC) provides precipitation observation with high temporal and spatial resolution. It is composed by three radars since 2003 and in 2008 a fourth one was added (not used in this study). Such a dense radar network -4 radars covering about $32000 \mathrm{~km}^{2}$ - was designed to cover the complex topography of the region in order to provide high quality Quantitative Precipitation Estimates (QPE). Figure 1 shows the volumetric radar coverage of the XRAD network and the XDDE sensor locations used in the present study.

The radars operate in C-Band $(5600-5650 \mathrm{MHz})$ and have Doppler capability. Their transmitters employ travelling wave tube (TWT) and have a peak power of $8 \mathrm{~kW}$, allowing improved sensitivity using pulse compression (O'Hora and Bech, 2007). The beamwidth of the radar antennas is approximately 1 degree; more details of the network are available in Bech et al. (2004).

Radar volumes include 15 Plan Position Indicator (PPI) scans every $6 \mathrm{~min}$ at short range $(150 \mathrm{~km}$ for the CDV radar and $130 \mathrm{~km}$ for the rest), and a long range $250 \mathrm{~km}$ base scan. The volumes of the 3 radars are combined in a composite volume by means of the maximum available reflectivity value at each point, generating a 10 level CAPPI (Constant Altitude Plan Position Indicator) product, with a spatial horizontal resolution of $2 \times 2 \mathrm{~km}^{2}$ and $1 \mathrm{~km}$ of vertical resolution. The coverage of the product is presented in Fig. 1 and an example of radar and lightning observations is shown in Fig. 2. The spatial and time resolutions allow for the making of a good analysis of thunderstorms, although sometimes they have tops exceeding the vertical coverage of this radar composite.

\subsection{Lightning data}

The SMC also operates a Total Lightning detection System (hereafter XDDE) which covers the region of Catalonia and the neighbouring area (Fig. 1). The system is currently composed by four detection stations, while the data for this study 


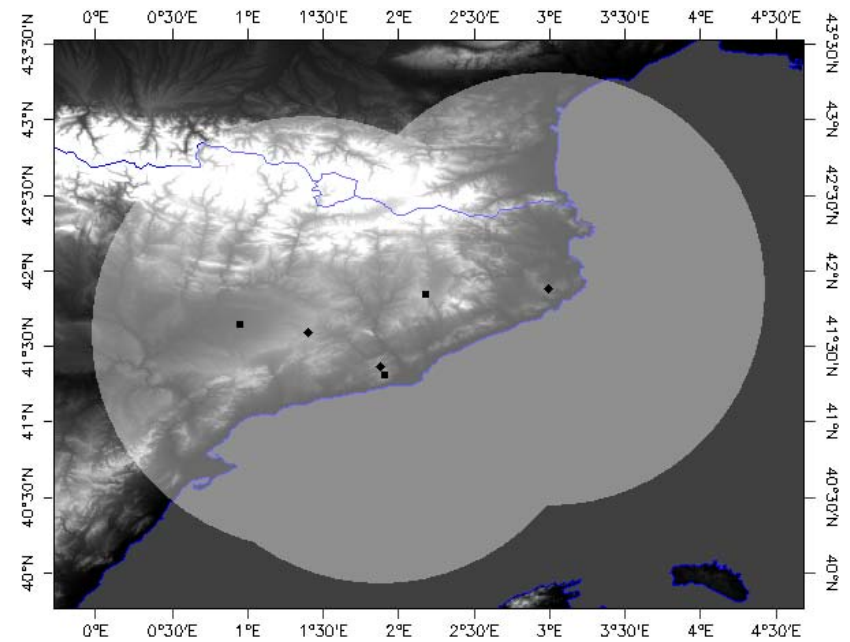

Fig. 1. Three dimensional radar coverage considered in this study. Radar (XRAD) and lightning (XDDE) sensor locations are marked, respectively, with diamond and square symbols.

was recorded under a previous three sensor configuration. The XDDE relies on SAFIR technology (Richard and Lojou, 1996) which uses an interferometric technique to detect intra-cloud and cloud-to-ground lightning. Each interferometer detects the direction of electromagnetic sources corresponding to leader phases of lightning discharges. The combination of different directions provides a two-dimensional location of the VHF sources. These interferometers operate in the VHF range from 110 to $118 \mathrm{MHz}$ with $0.6 \mathrm{MHz}$ of bandwidth. The identification of each source as isolated, considering beginning of flash, end of flash, or intermediate source, is performed on the basis of spatial and temporal criteria. For the XDDE, these criteria have been established so that two successive VHF sources can be associated in the same intra-cloud flash if spatial and temporal intervals between them are lower than $7 \mathrm{~km}$ and $100 \mathrm{~ms}$, respectively. On the other hand, detection of CG return strokes is performed by a sensor working in the LF range $(300 \mathrm{~Hz}$ and $3 \mathrm{MHz})$. Strokes are grouped into CG flashes considering a multiplicity delay of $0.5 \mathrm{~s}$ in a radius of $7 \mathrm{~km}$. The SAFIR sensors allow the computing of 100 detections per second.

The XDDE provides 2-D location of isolated VHF sources, 2-D intracloud (IC) trajectories and CG lightning flash characteristics (time, 2-D location, polarity, peak current and multiplicity). The XDDE has been experimentally evaluated with two field measurement campaigns (Montanyà et al., 2006; Pineda and Montanyà, 2009). According to them, the detection efficiency ranges between 86 and 92\%, in agreement with the manufacturer specifications, and the flash location precision is around $1 \mathrm{~km}$.

A previous analysis of the XDDE data from the period 2003-2007 for Catalonia (Pineda and Montanyà, 2009) has shown that summer has the major concentration of annual

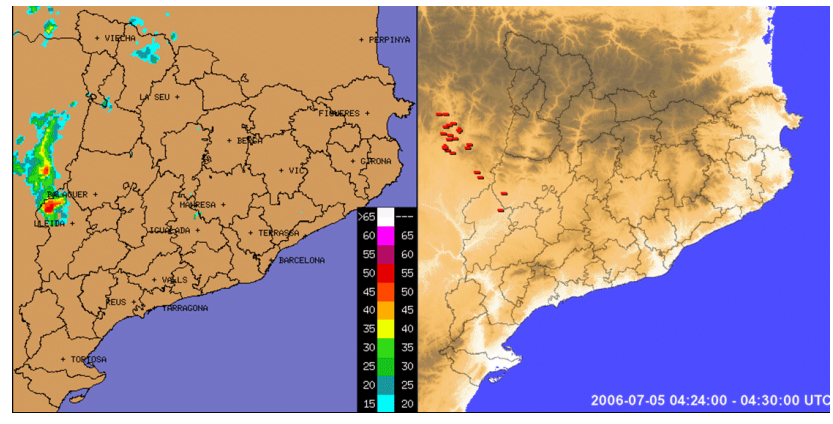

Fig. 2. Example of a 1-km a.s.l. radar reflectivity composite CAPPI product (left) and CG lightning observations (right), at 04:30 UTC of 5 July 2006.

CG flash counts, in agreement with previous studies over the whole Iberian Peninsula with a longer database (1992-2001) (Rivas Soriano et al., 2005). Between July and September there are typically more than $70 \%$ of the registered yearly flashes of the region. The present work considers thunderstorm events in the period from 1 July to 15 September 2006 , in which $85 \%$ of the annual lightning records were registered.

\subsection{Radiosonde and NWP wind data}

Additionally, radiosonde data from the SMC Barcelona station (WMO code 08190) and the MASS model wind forecasts (Bech et al., 2007a) were used. The Barcelona radiosonde is launched twice daily and it has been used in the present work to determine the $-20^{\circ} \mathrm{C}$ and $-40^{\circ} \mathrm{C}$ isotherm levels. The MASS model ( $8 \mathrm{~km}$ horizontal grid resolution) provided wind profiles. This information is integrated with the previous motion of the thunderstorm for providing a new vector, which will be used as the future movement of the thunderstorm.

\section{Methodology}

In this section, an object-oriented methodology to identify and track precipitating structures is presented (Subsect. 4.1 and 4.2), and also a statistical methodology to analyse the life-cycle of convective structures (Subsect. 4.3).

\subsection{Identification of precipitating structures}

The identification scheme applied considers four types of primary objects obtained from different data products, which are all combined into a higher-level object, which represents the precipitating structure. The four types of primary objects considered are: RAD2 (2-D radar based product), RAD3 (volumetric radar based product), XDG (CG based product) and XDC (IC based product).

RAD2 structures are identified in the lowest elevation CAPPI product ( $1 \mathrm{~km}$ altitude) of the radar reflectivity 
composite using the following procedure: first, radar reflectivity pixels exceeding $12 \mathrm{dBZ}$ are considered as "rainfall echoes", and the rest are neglected. Next, connected rainfall pixels are aggregated. If the aggregations have an area below $24 \mathrm{~km}^{2}$ they are also discarded, in order to avoid nonprecipitation echoes - such as ground clutter or anomalous propagation. Finally, rainfall type, i.e. convective and stratiform regions, is separated using the following criteria: convective regions are those where the $43 \mathrm{dBZ}$ threshold is exceeded or its background verifies a gradient condition (Rigo and Llasat, 2004); the rest of the regions are considered as stratiform (Fig. 3). Once RAD2 objects have been identified, some parameters are obtained in order to characterise them: position of the centroid, area, reflectivity, rain rate, vertical development and percentage of all types of precipitation (convective and stratiform). Finally, RAD2 objects which generally present an irregular shape are converted into ellipses, to allow a simpler tracking methodology. The conversion from the original RAD2 shape into an ellipse is made imposing that the original area and orientation of the eigen vectors are conserved, as proposed by Riosalido (1994) in a similar application.

RAD3 objects identification is done analysing the complete tridimensional radar reflectivity data volume made up of 10 CAPPIs. A RAD3 object has a minimum vertical extension of 2 levels, a minimum horizontal area of $18 \mathrm{~km}^{2}$ at each level and a minimum reflectivity threshold of $35 \mathrm{dBZ}$ following the scheme proposed by Johnson et al. (1998). A RAD3 object can be considered as a volume of radar echoes associated with the core, or the most intense part, of a convective cell. The main features of RAD3 objects include position of centroid $(x, y, z)$, altitude of the top and base of the structure, total volume and reflectivity (Fig. 3).

XDC and XDG object identification is done with a similar procedure to RAD2, but applied to IC and CG data. The identification is made with the same time resolution as radar data $(6 \mathrm{~min})$ over the same 2-D horizontal grid of the radar CAPPI product to allow later the combination of all objects. The first step is to convert point measurements of flashes in grid pixel flash counts, flagging pixels with lightning activity. Then, those flagged pixels that are closer than $5 \mathrm{~km}$ are considered connected. Later, all connected pixels are grouped into regions that define the XDC and XDG objects. Finally, the characteristics of each object are determined: area, centroid position, total flash count and maximum and mean flash density (Fig. 3).

Once all the radar and lightning primary objects are identified, they are all integrated in a higher-level object, the precipitating structure that defines the thunderstorm in a precise moment. The integration is made on the basis of combining objects with common pixels. The intersection of the four different fields of objects (RAD2, RAD3, XDC and XDG) generates the field of precipitating structures. The final shape of the precipitating structures results from the application of a morphological growth filter to include nearby objects which might not be connected. This filtering is based on Haralick et al. (1987), a nonlinear method of processing digital images on the basis of shape attributes to quantify geometrical structures and their changes. Finally, parameters of the precipitating structures are calculated: total area, centroid position, and all the parameters associated with the radar (2-D and 3-D) and electrical parameters (IC and CG).

\subsection{Tracking}

For each type of radar object, a different tracking algorithm is applied. RAD2 tracking methodology checks the intersection of object areas in consecutive images; a minimum area threshold of $80 \%$ identifies a RAD2 object in two consecutive time frames. In the case of RAD3, the tracking is applied considering several aspects: the distance between the position of the centroids in two consecutive images (limited to a maximum of $10 \mathrm{~km}$ ), and the evolution of parameters such as volume or reflectivity, which must follow an increasedecrease trend. If these conditions are not met then a new RAD3 object is considered, identified as a daughter of the previous one. No tracking of XDC and XDG objects is performed.

After RAD2 and RAD3 objects have been computed, a tracking of precipitating structures is calculated. The methodology applied is the same used for the RAD2 objects. Tracking precipitating structures allows for the observation of combined radar and lightning data in real-time, highlighting those regions where hazardous weather (elevated flash rates, high rain rate, hail...) associated with thunderstorms is more likely. Furthermore, the combination of both types of data allows tracking structures in regions where one of the two data sources are partially blocked (for example, due to radar beam blockage) or temporally unavailable.

\subsection{Statistical analysis}

The identification and tracking described above has been applied to the period from 1 June to 15 September 2006 in the region of study. With this methodology 425 precipitating structures were detected and tracked. The spatial distribution of these structures was analysed with the purpose of determining prone areas to convection initiation. In order to consistently study the life cycle of thunderstorms, i.e. precipitating structures with lightning, the analysis was restricted to the cases that verified the following conditions:

- The life cycle duration exceeded $50 \mathrm{~min}$.

- The whole life cycle was observed in the region of tridimensional coverage of the SMC radar network.

- All four different object types (RAD2, RAD3, XDC, $\mathrm{XDG})$ were present at some stage of the life cycle.

- Neither fusion nor fission processes were observed during the life cycle. 
a)

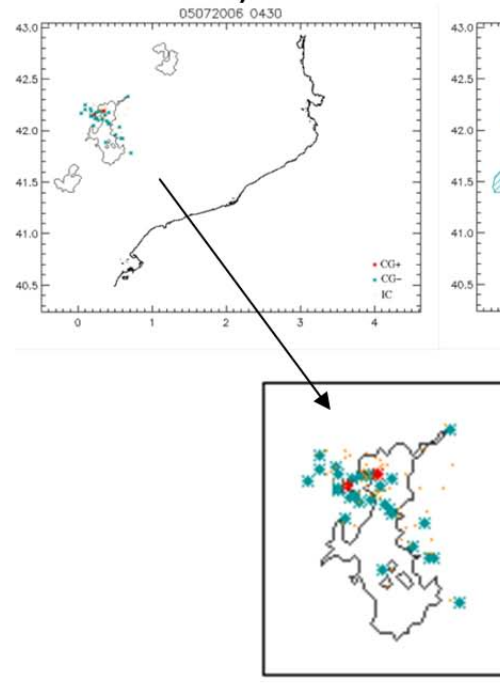

b)
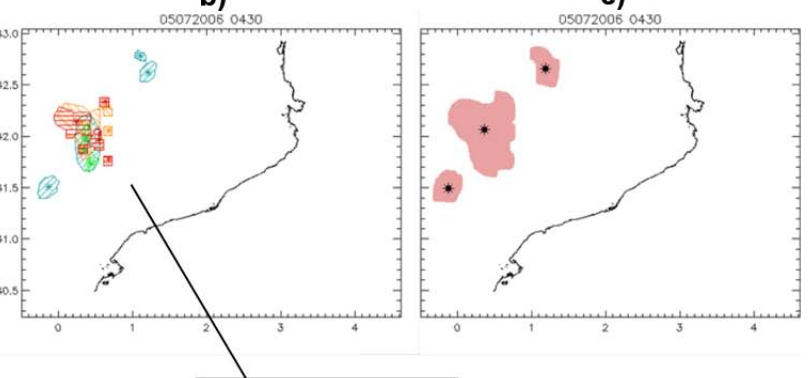

Fig. 3. Example of object identification methodology (same date and time as Fig. 2). (a) Radar reflectivity areas exceeding $12 \mathrm{dBZ}$ are indicated by thin black lines overlayed to + CG (red asterisks), -CG (blue asterisks), and IC flashes (red dots). (b) RAD2 (blue), RAD3 (green), XDC (orange), and XDG (red) first level objects. (c) Thunderstorm structures and their centroids after combining the first level objects shown in (b). Bottom row shows zooms of (a) and (b).

These conditions were met by 66 precipitating structures whose characteristics were examined statistically in more detail. The analysis of thunderstorm characteristics included duration, number and rate of flashes, positive anomalies $(+\mathrm{CG}>-\mathrm{CG})$, area, mean reflectivity, convective rainfall and rain rate, and intervals with high possibility of hail (reflectivity $>55 \mathrm{dBZ}$ ). For the sake of simplicity, this last criterion is defined considering only radar reflectivity data, though at the SMC a more sophisticated hail diagnostic product based on radar and NWP data is operationally used (see Aran et al., 2007 for details).

All these variables were computed for each stage of the thunderstorm (development, maturity and dissipation). The change from development to maturity was determined by considering the following:

- $12 \mathrm{dBZ}$ echo tops exceeded and stayed above the $-40^{\circ} \mathrm{C}$ isotherm level.

- Decrease of the growth rate of IC flashes, compared to the development stage.

- Decrease of areal extension growth rate, compared to the development stage.

The change from maturity to dissipation stage was detected considering:

- $12 \mathrm{dBZ}$ echo tops below the $-40^{\circ} \mathrm{C}$ isotherm level.

- Continuous decrease of the IC flash rate, compared to the maturity stage.

- Continuous decrease of the thunderstorm area.
Moreover, the general life cycle patterns were also studied considering the time series of five different variables of each thunderstorm (area, maximum reflectivity, echo top, and IC and CG flash rates). Normalising these time series with respect to their duration and maximum values a simplified life cycle pattern is derived and discussed.

\section{Results and discussion}

\subsection{Geographical and temporal characteristics}

One aspect examined for each of the 425 storms in the dataset is the initial location and time, which are outlined in this section. The spatial distribution of the initial location of precipitating structures studied here is shown in Fig. 4. It indicates that there exist regions more favourable to thunderstorm initiation than others. In particular, three different zones, associated with topographical features must be remarked: the Pyrenees (Northern part), the Iberian System mountain range (W and SW region), and the Southern and Central Coastal region, where more than 5 precipitating structures were initiated in several grid cells. Regarding the time of initialization and end of each structure, most of them began close to 13:00 UTC - just after the time of maximum solar irradiance - and end at approximately 18:00 UTC, which suggests a strong influence of the diurnal cycle on the thunderstorms examined. 
Table 1. Summary of thunderstorms, lightning and radar derived characteristics.

\begin{tabular}{|c|c|c|c|c|}
\hline & \multirow[t]{2}{*}{ Total } & \multicolumn{3}{|c|}{ Life cycle stage } \\
\hline & & Devel. & Matur. & Dissip. \\
\hline \multicolumn{5}{|l|}{ Average (median) phase } \\
\hline duration [min] & $204(192)$ & $48(36)$ & $108(96)$ & $48(42)$ \\
\hline IC flash [\%] & & $2.4 \%$ & $85.8 \%$ & $11.8 \%$ \\
\hline CG flash [\%] & & $2.9 \%$ & $85.8 \%$ & $11.3 \%$ \\
\hline Average IC rate $\left[\mathrm{min}^{-1}\right]$ & 9.9 & 1.0 & 16.0 & 4.9 \\
\hline Average CG rate $\left[\mathrm{min}^{-1}\right]$ & 4.0 & 0.5 & 6.5 & 1.9 \\
\hline Average area $\left[\mathrm{km}^{2}\right]$ & 509 & 323 & 631 & 503 \\
\hline Average reflectivity [dBZ] & 43.8 & 40.6 & 47.1 & 42.9 \\
\hline Convective rainfall [\%] & $38.2 \%$ & $43.8 \%$ & $39.8 \%$ & $33.4 \%$ \\
\hline Average rain rate $[\mathrm{mm} / \mathrm{min}]$ & 1.3 & 0.7 & 1.8 & 1.1 \\
\hline
\end{tabular}

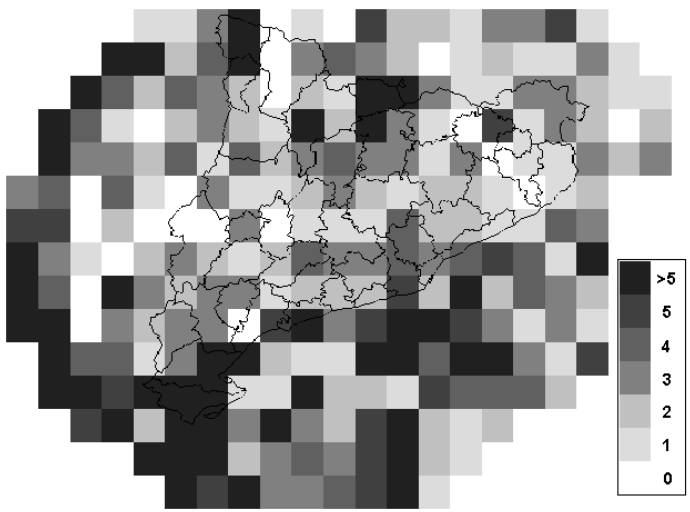

Fig. 4. Initial location of thunderstorms examined in this study. The grey scale indicates the number of times a thunderstorm has initiated in each grid cell of the region of study.

\subsection{Life cycle features}

The general features of the life cycle of the 66 thunderstorms selected that verified the criteria described in the previous section are shown and discussed in the following paragraphs. Table 1 presents a summary of characteristics of the selected thunderstorms, detailing also the proportion of each life cycle stage to the total duration.

Thunderstorms examined have a life cycle between $54^{\prime}$ to approximately $8 \mathrm{~h}$, although the mean duration was about $3.5 \mathrm{~h}$ (204 min). Average durations of the development and dissipation stages are quite similar, while maturity is notably longer. It is in this stage where most lightning activity is observed (more than $80 \%$ of the IC and CG flashes recorded of the whole thunderstorm duration). In spite of the simi- lar duration of the development and dissipation stages, in the latter the flash rate activity for both types of lightning was substantially higher. On the other hand, average CG flash rate is higher during the maturity stage $\left(\sim 5 \mathrm{~min}^{-1}\right)$ than in the initial and final stages.

Regarding the radar derived parameters, maximums of reflectivity, and the associated rain rates, are detected in the maturity phase (with differences of about $5 \mathrm{~dB}$ between the average maximums), while the percentage of convective precipitation reaches its maximum in the developing stage.

Average polarity of CG flashes in the analysed cases is mainly negative. However, some short periods of positive polarity predominance, i.e., where positive CG outnumber negative ones, have been observed in 6 of the 66 studied cases lasting between 6 to $18 \mathrm{~min}$. The dominance of positive CG could be associated with severe weather (Lang and Rutledge, 2002; Dotzek and Price, 2009). In our dataset in 2 of these 6 cases large hail was observed.

The examined thunderstorms have been classified into three groups, according to the CG flash rate during the maturity stage (Table 2): weak, moderate and heavy. The thresholds for each group are used routinely at the SMC for thunderstorm surveillance tasks.

The analysis of the previous classification can be summarized by the following points:

- The more intense the thunderstorm, the longer the duration.

- The maturity is the stage that contributes most to the differences between durations of the different intensity classes. In weak thunderstorms, this stage has a similar duration than the initial and final stages. In heavy 
Table 2. Categories of the studied thunderstorms according to CG flash rate.

\begin{tabular}{lccccccc}
\hline Intensity & $\begin{array}{c}\text { Average CG } \\
\text { flash rate } \\
{\left[\mathrm{min}^{-1}\right]}\end{array}$ & $\begin{array}{c}\text { Number of } \\
\text { thunder-storm }\end{array}$ & $\begin{array}{c}\text { Range of CG } \\
\text { flash rate } \\
{\left[\mathrm{min}^{-1}\right]}\end{array}$ & \multicolumn{4}{c}{ Average duration [min] } \\
\hline Weak & $<2$ & 28 & $0.1-1.7$ & 165 & 42 & 78 & 45 \\
Moderate & $2-10$ & 28 & $2.1-6.1$ & 210 & 52 & 111 & 47 \\
Heavy & $>10$ & 10 & $10.1-43.9$ & 290 & 45 & 181 & 64 \\
\hline
\end{tabular}

thunderstorms the sum of the development and dissipation durations represents only $60 \%$ of the duration of the middle stage.

- There is a clear positive correlation $\left(R^{2}=0.580, n=\right.$ 66) between the duration of the maturity stage and the logarithm of the CG flash counts observed during the same phase (see Fig. 5). This result agrees with a similar analysis made in Florida (Peckham et al., 1984).

- Radar parameters analysed exhibited average maximum values during the maturity stage, except the percentage of convective precipitation which had its maximum in the development stage. Another remarkable feature of radar-derived parameters is that they follow similar increase/decrease trends to lightning flash rates throughout the thunderstorm life cycle.

The next step of the life cycle analysis was the distinction between thunderstorms with a unique vertical development and those with more than one. Only 38\% of the 66 analysed cases had one single vertical development. To illustrate this difference Fig. 6 presents an example of both types of thunderstorms. Moreover, it has been found that in most cases the higher the CG flash rate of the thunderstorms, the higher the probability of observing one or more successive vertical developments after the first one.

\subsection{Generalized life-cycle patterns}

Despite the wide variety of behaviours of thunderstorm lightning and radar-derived parameters considering the results shown in the previous sections, it seems reasonable to look for possible generalized patterns of the thunderstorm lifecycle parameters. Previous studies have been devoted to examining general features of larger scale convective systems, as in McAnelly and Cotton (1989) or Mapes et al. (2006). Here we focus on the analysis of the thunderstorms whose general characteristics have been described earlier. This question, if applicable, is important in terms of operative weather surveillance: if the stage of a thunderstorm life cycle can be determined reliably, the generalized pattern could then be used to infer the evolution of its lightning and radar parameters. To look for possible generalized life-cycle patterns,

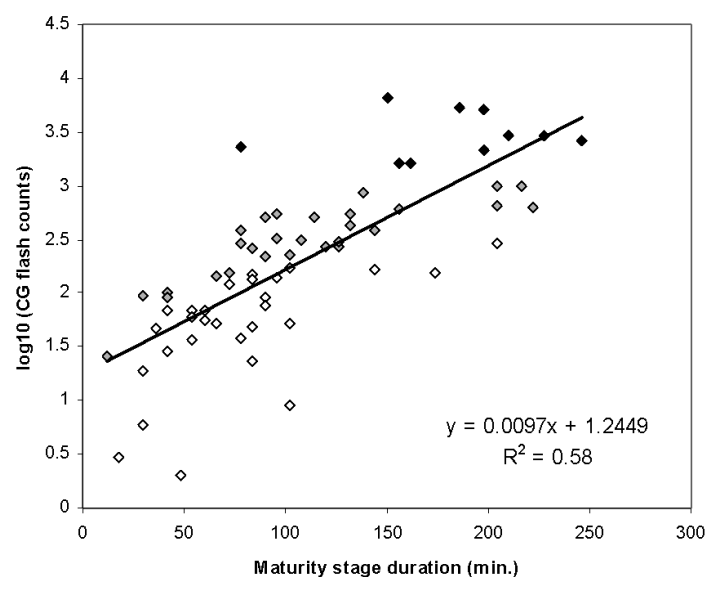

Fig. 5. Positive correlation $\left(R^{2}=0.580, n=66\right)$ between the duration of the maturity stage and the logarithm of the CG flash counts observed during the same phase. Colours correspond to the intensity categories: weak (white), moderate (grey) and strong (black).

the different variables examined (area, IC and CG rate densities), the proportion of convective precipitation and maximum values in the RAD2 (1-km CAPPI reflectivity composite) and RAD3 (volumetric reflectivity composite) objects have been normalized with respect to the maximum value of the magnitude and with respect to time. This allows comparing all life cycles of a given magnitude in relative terms. Plots showing the evolution of those parameters have been constructed and examined. As the dispersion of the normalized curves is rather high, in order to visualize possible general thunderstorm life-cycle patterns, the 25, 50 and $75 \%$ (denoted here as P25, P50 and P75, respectively) have been calculated for each normalized time period.

Figure 7 shows the normalized evolutions of four magnitudes for the 66 selected cases: thunderstorm area, IC flash density, percentage of convective precipitation, and maximum reflectivity at $1-\mathrm{km}$ a.s.l. The percentile curves help to detect the general behaviour of the magnitudes during the life cycle of the thunderstorm: an initial phase of development, an intermediate stage where the evolution of the parameter generally stabilizes and, finally, the stage of dissipation. Note that these stages are apparent in 3 out of 4 magnitudes shown. 

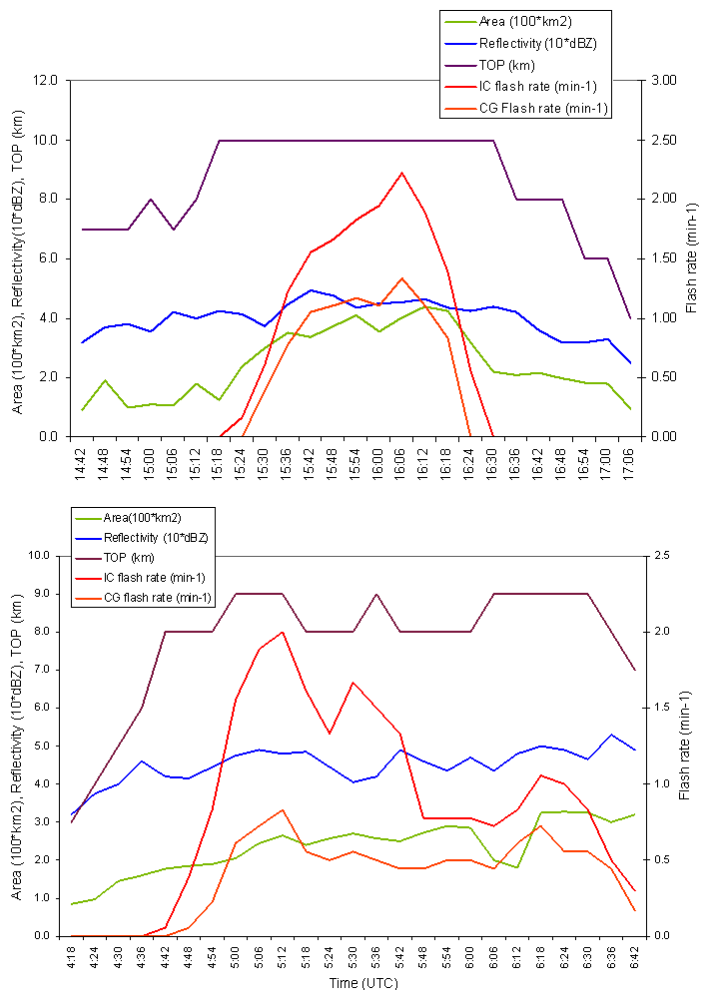

Fig. 6. Two examples of thunderstorms life cycles: single cell with a unique development (top), and a structure with more than one vertical development (successive maxima) (bottom).

Figure $7 \mathrm{a}$ shows the normalized thunderstorm area plots with the P25, P50 and P75 percentiles. It indicates that 50\% of thunderstorms have an initial stage lasting about $35 \%$ of the total time. The intermediate stage takes place from $35 \%$ to $75 \%$ of the life cycle - most thunderstorms reach their maximum area during this stage. Finally, the dissipation stage, the shortest of the three phases, corresponds to the last $25 \%$ of the time. Moreover the difference between P75 and P25 is nearly constant along the life cycle (ranging approximately $20 \%$ of the normalized area).

Figure $7 \mathrm{~b}$ presents the normalized IC flash density with the corresponding quartile curves. In this case the median follows an asymmetric pattern with a maximum at about $40 \%$ of the life cycle followed by a gentle decrease which accelerates at about $80 \%$ of the normalized time; the CG flash density pattern is very similar (not shown here). Another remarkable difference with the quartiles of the normalized area curves is that the inter-quartile range now is not constant and ranges between $20 \%$ and $50 \%$ in the central stage. Moreover, the median is relatively low (below $45 \%$ of the normalized maximum), indicating that maximum lightning flash counts are relatively sharp and brief compared to the average values throughout the thunderstorm.

Figure $7 \mathrm{c}$ shows the normalized convective precipitation percentage and associated quartiles, presenting a different pattern with respect to the other 3 displayed magnitudes. The most significant characteristic is that the quartiles now follow a monotonically decreasing trend along the thunderstorm life cycle. This can be explained in general terms by the fact that the thunderstorm development stage is characterised by the predominance of vertical ascending air motions which generate convective precipitation (median above $80 \%$ at the beginning). As the anvil develops, the proportion of nonconvective precipitation increases until the end of the life cycle when it reaches $50 \%$ of the total.

Finally, Fig. 7d shows the 1-km CAPPI maximum reflectivity normalized curves with the corresponding quartiles. In this case, the P25, P50 and P75 are above $60 \%$ of the normalized maximum. From 10 to $80 \%$ of the life cycle, the inter-quartile range remains rather constant (below 20\%), indicating that relative maximum reflectivity is quite similar among the different cases. However, the general evolution is similar to the previous cases, presenting the three typical stages: initial, intermediate and final.

Figure 8 summarizes the normalized evolution of the P50 for the whole of the analysed variables. These magnitudes, besides those commented previously, are RAD2 and RAD3 radar reflectivity echo tops, and RAD3 maximum reflectivity. Note that the median of the RAD2 echo top reaches the $100 \%$ level between $30 \%$ and $45 \%$ of the life cycle normalized duration. This saturation effect may be explained by the $10 \mathrm{~km}$ threshold applied to the radar data used in this study, while $12 \mathrm{dBZ}$ top heights observed attained higher altitudes.

Regarding the different behaviour of both the 3-D structure parameters shown in Fig. 8, it must be taken into account the thresholds used in the definition of the thunderstorm structure. The total duration of the thunderstorm is generally determined by the RAD2 object duration, and only when the thunderstorm achieves a higher degree of development are the features of the RAD3 considered. The existence of RAD3 is observed in more or less $50 \%$ of the whole life cycle period in which the highest vertical developments are detected, also for the top of RAD2. Finally, the percentage of convective precipitation is the unique parameter that has a different pattern than the growing-decreasing behaviour. In this case, the magnitude basically decreases along the whole life cycle, indicating that the convective precipitation processes tend to lose presence in the structure mechanisms.

\section{Summary and conclusions}

The main objective of this work was the integration of lightning and radar data, developing a tool for real-time analysis of the evolution of the thunderstorms. This tool has been applied to Catalonia and surrounding areas in order to improve thunderstorm surveillance and nowcasting tasks. For this purpose, an object-oriented methodology to identify, characterise and track thunderstorms in real-time has been demonstrated. 

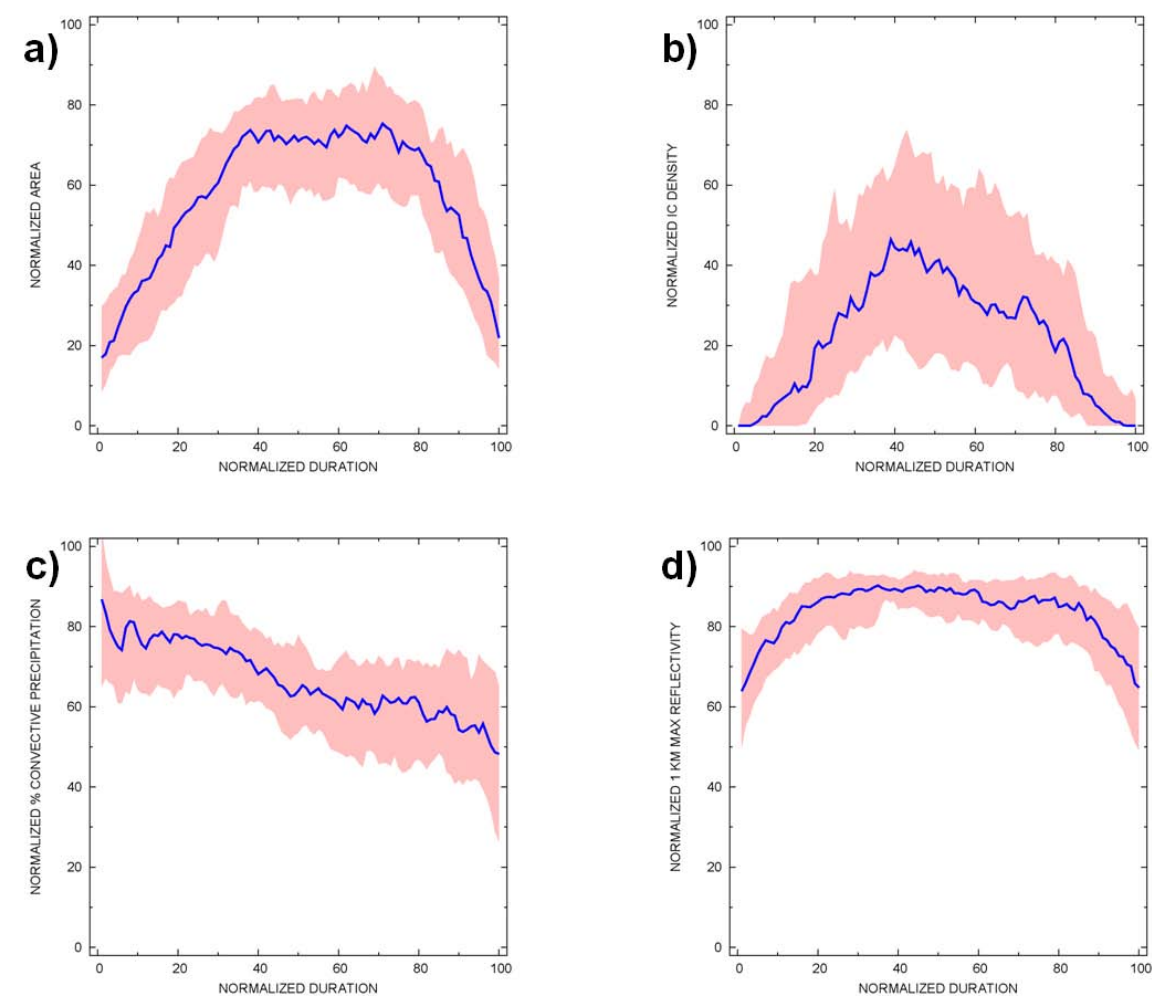

Fig. 7. Temporal evolution for different magnitudes of convective structures normalized with respect to maximum values reached (y-axis) and duration (x-axis). Each panel shows the area between the 25 and 75 percentile curves shaded and the 50 percentile curve (median) as a thick line. Normalized thunderstorm magnitudes shown are: (a) area; (b) intra-cloud flash; (c) proportion of convective precipitation; and (d) maximum reflectivity at 1-km CAPPI level.

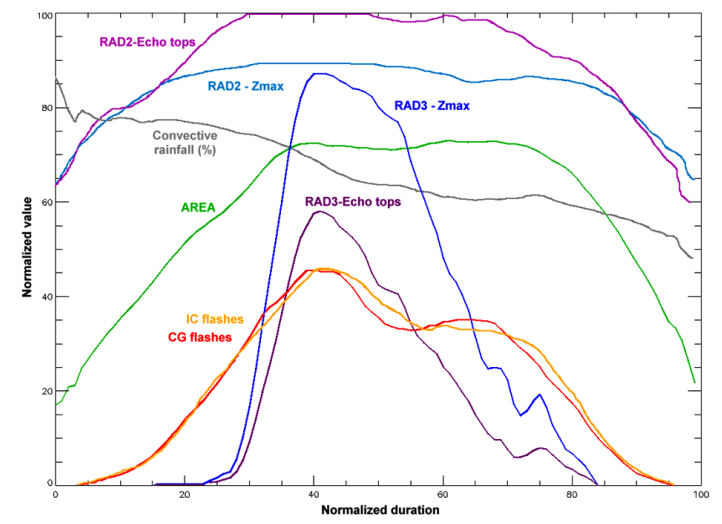

Fig. 8. Normalized plots of 50 percentile curves (medians) of different parameters: radar reflectivity echo tops (RAD2 and RAD3), $\mathrm{Z}_{\text {max }}(\mathrm{RAD} 2$ and RAD3), thunderstorm area, thunderstorm convective rainfall, and IC and CG flash rate.

The object-oriented methodology considers four types of primary objects from different data and lightning data products, which are combined into a higher-level object, representing the thunderstorm. The four types of primary objects considered are: RAD2 (2-D radar based product), RAD3 (volumetric radar based product), XDG (CG based product) and XDC (IC based product). After thunderstorms are identified, a tracking methodology is applied in order to characterise life cycles of the convective structures.

This procedure has been tested with 66 thunderstorms observed from 1 July 2006 to 15 September 2006 which verified the following conditions: their duration exceeded one hour; their complete life cycle was within the coverage area; and they did not present merging and splitting during their life cycle.

The analysis of the results has been performed considering three different thunderstorm stages (development, maturity and dissipation) and also three types of thunderstorm intensity according to their maturity stage CG flash rate (weak, moderate and heavy). The different thunderstorm stages have been determined considering the evolution of the IC flash rate, the total area of the thunderstorm, and the $12 \mathrm{dBZ}$ radar echo top.

The results indicate that the development and dissipation stages present similar durations in most cases examined. On the contrary, the duration of the maturity phase is much more variable and related to the thunderstorm intensity. In the case of heavy thunderstorms the mean duration of the maturity stage doubles the sum of the development and dissipation stages. Most of the activity of IC and CG flashes is registered in the maturity stage: about $90 \%$ of all thunderstorm 
CG counts for heavy cases and $80 \%$ for the others. In the development stage little CG flashes are observed (2\% to $5 \%$ ), while for the dissipation phase is possible to observe a few more CG flashes (10\% to $15 \%$ ). This activity, at the end of the life cycle, is important for surveillance tasks as dissipating thunderstorms may still be dangerous until they end completely.

Other radar-derived parameters of thunderstorms such as maximum reflectivity, total area and estimated areal precipitation were found to be related to the thunderstorm intensity. Thus, for the most intense thunderstorms these parameters tend to register higher values. On the other hand, the percentage of convective precipitation is phase related: higher values are observed in the beginning of the life cycle. While the thunderstorm evolves and the anvil develops, stratiform precipitation increases and convective rainfall tends to disappear.

Furthermore, it is planned to introduce nowcasting procedures with the purpose of generating a very short range forecast product, in order to support operational forecasters to take decisions in the surveillance and warning of convective events at SMC.

Acknowledgements. We appreciate the constructive comments of two anonymous reviewers who contributed to improve the clarity of this paper.

Edited by: A. Mugnai

Reviewed by: E. Galanti and another anonymous referee

\section{References}

Aran, M., Sairouni, A., Bech, J., Toda, J., Rigo, T., Cunillera, J., and More, J.: Pilot project for intensive surveillance of hail events in Terres de Ponent (Lleida), Atmos. Res., 83, 315-335, 2007.

Barnolas, M. and Llasat, M. C.: A flood geodatabase and its climatological applications: the case of Catalonia for the last century, Nat. Hazards Earth Syst. Sci., 7, 271-281, doi:10.5194/nhess-7271-2007, 2007.

Bech, J., Codina B., and Lorente, J.: Forecasting weather radar propagation conditions, Meteorol. Atmos. Phys., 96, 229-243, 2007a.

Bech, J., Pascual, R., Rigo, T., Pineda, N., López, J. M., Arús, J., and Gayá, M.: An observational study of the 7 September 2005 Barcelona tornado outbreak, Nat. Hazards Earth Syst. Sci., 7, 129-139, doi:10.5194/nhess-7-129-2007, 2007b.

Bech, J., Vilaclara, E., Pineda, N., Rigo, T., López, J., O’Hora, F., Lorente, J., Sempere, D., and Fábregas, F. X.: The weather radar network of the Catalan Meteorological Service: description and applications, Proceedings of ERAD 2004, 416-420, Visby, Sweden, Copernicus GmbH, 2004.

Bonelli, P. and Marcacci, P.: Thunderstorm nowcasting by means of lightning and radar data: algorithms and applications in northern Italy, Nat. Hazards Earth Syst. Sci., 8, 1187-1198, doi:10.5194/nhess-8-1187-2008, 2008.

Brovelli, P., Sénési, S., Arbogast, E., Cau, P., Cazabat, S., Bouzom, M., and Reynaud, J.: Nowcasting thunderstorms with Sigoons a significant weather object oriented nowcasting system, Proceedings of the International Symposium on Nowcasting and Very Short Range Forecasting (WSN05), Toulouse, France, 2005.

Buechler, D. E. and Goodman, S. J.: Echo size and asymmetry: impact on NEXRAD storm identification, J. Appl. Meteor., 29, 962-969, 1990.

Carey, L. D. and Rutledge, S. A.: A multiparameter radar case study of the microphysical and kinematic evolution of a lightning producing storm, Meteor. Atmos. Phys, 59, 33-64, 1996.

Creutin, J. D., Borga, M., Lutoff, C., Scolobig, A., Ruin, I., and Créton-Cazanave, L.: Catchment dynamics and social response during flash floods: the potential of radar rainfall monitoring for warning procedures, Met. Appl., 16, 115-125, 2009.

Demetriades, N., Murphy, M., and Richard, P.: The advantages of total lightning over CG lightning for thunderstorms cell identification and tracking and its complements to radar reflectivity, Proceedings of the 12th International Conference on Atmospheric Electricity, Versailles, France, 2003.

Dixon, M. and Wiener, G.: TITAN: Thunderstorm identification, tracking, analysis and nowcasting - A radar-based methodology, J. Atmos. Ocean. Tech., 10, 785-797, 1993.

Doswell III, C. A., Brooks , H. E., and Maddox, R. A.: Flash flood forecasting: An ingredients-based methodology, Weather Forecast., 11, 560-581, 1996.

Doswell III, C. A.: Severe convective storms - an overview, Severe Convective Storms, Meteor. Monogr., 28(50), Amer. Meteor. Soc., 1-26, 2001.

Dotzek, N. and Price, C.: Lightning characteristics of extreme weather events, in: Lightning: Principles, Instruments and Applications, edited by: Betz, H.-D., Schumann U., and Laroche P., Springer, 487-507, 2009.

Goodman, S. J.: Predicting thunderstorm evolution using groundbased lightning detection networks, NASA Tech. Memo NASA TM-103521, 193 pp., 1990.

Hand, W. H. and Conway, B. J.: An object-oriented approach to nowcasting showers, Weather Forecast., 10, 327-341, 1996.

Handwerker, J.: Cell tracking with TRACE3D - a new algorithm, Atmos. Res., 61(1), 15-34, 2002.

Haralick, R. M., Sternberg, S. R., and Zhuang, X.: Image analysis using mathematical morphology, IEEE Transactions on Pattern Analysis and Machine Intelligence PAMI-9, 4, 532-550, 1987.

Hering, A. M., Ambrosetti, P., Germann, U., and Sénési, S.: Operational nowcasting of thunderstorms in the Alpine area, Proceedings of the 4th European Conference on Severe Storms, Trieste, 10-14 September, 2007.

Hering, A. M., Sénési, S., Ambrosetti, P., and Bernard-Bouissiéres, I.: Nowcasting thunderstorms in complex cases using radar data, Proceedings of the International Symposium on Nowcasting and Very Short Range Forecasting (WSN05), Toulouse, France, 2005.

Jansá, A., Genovés, A.,. Picornell, M. A., Campins, J., Riosalido, R., and Carretero, O.: Western Mediterranean Cyclones and Heavy Rain - Part 2: Statistical Approach, Meteorol. Appl., 8, 43-56, 2001.

Johnson, J. T., MacKeen, P. L., Witt, A. E.,. Mitchell, E. D., Stumpf, G. J., Eilts, M. D., and Thomas, K. W.: The storm cell identification and tracking algorithm: an enhanced WSR-88D algorithm, Weather Forecast., 13, 263-276, 1998.

Keenan, T., Joe, P., Wilson, J., Collier, C., Golding, B., Burgess, D., 
May, P., Pierce, C., Bally, J., Crook, A., Seed, A., Sills, D., Berry, L., Potts, R., Bell, I., Fox, N., Ebert, E., Eilts, M., O’loughlin, K., Webb, R., Carbone, R., Browning, K., Roberts, R., and Mueller, C.: The Sydney 2000 World Weather Research Programme Forecast Demonstration Project: Overview and current status, B. Am. Meteorol. Soc., 84, 1041-1054, 2003.

Kyznarová, H. and Novák, P.: CELLTRACK - Convective cell tracking algorithm and its use for deriving life cycle characteristics, Atmos. Res., 93(1-3), 317-327, 2009.

Lang, T. J. and Rutledge, S. A.: Relationships Between Convective Storm Kinematics, Microphysics, and Lightning, Mon. Weather Rev., 130, 2492-2506, 2002.

Li, L., Schmid, W., and Joss, J.: Nowcasting of Motion and Growth of Precipitation with Radar over a Complex Orography, J. Appl. Meteor., 34, 1286-1300, 1995.

Llasat, M. C.: An objective classification of rainfall events on the basis of their convective features, Application to rainfall intensity in the North-East of Spain, Int. J. Climatol., 21, 1385-1400, 2001.

MacGorman, D. R. and Rust, W. D.: The Electrical Nature of Storms, Oxford University Press, New York, 403 pp., 1998.

MacGorman, D. R., Burgess, D. W., Mazur, V., Rust, W. D., Taylor, W. L., and Johnson, B. C.: Lightning rates relative to tornadic storm evolution on 22 May 1981, J. Atmos. Sci., 46, 221-250, 1989.

Mapes, B., Tulich, S., Linb, J., and Zuidema, P.: The mesoscale convection life cycle: Building block or prototype for large-scale tropical waves?, Dyn. Atmos. Oceans., 42, 3-29, 2006.

Martín, F., Elizaga, F., San Ambrosio, I., and Fernández, J. M.: recent progress in convective phenomena monitoring and forecasting at the INM, Proceedings of the International Symposium on Nowcasting and Very Short Range Forecasting (WSN05), Toulouse, France, 2005.

Martín, F., Carretero, O., and Elizaga, F.: Lightning and radar data observations of convective perturbations in the western mediterranean areas, 3rd EGS Plinius Conference, Baja Sardinia, Italy, 2001

McAnelly, R. L. and Cotton, W. R.: The Precipitation Life Cycle of Mesoscale Convective Complexes over the Central United States, Mon. Weather Rev., 117, 784-808, 1989.

Medaglia, C. M., Adamo, C., Formenton, M., and Piccolo, F.: Nowcasting of convective cells over Italian Peninsula, Adv. Geosci., 2, 173-176, doi:10.5194/adgeo-2-173-2005, 2005.

Montanyà, J., Pineda, N., March, V., Illa, A., Romero, D., and Solá, G: Experimental evaluation of the Catalan Lightning Location Network, in: 19th Int. Lightning Detection Conf., Tucson (AZ), USA, 2006.

O'Hora, F. and Bech, J.: Improving weather radar observations using pulse-compression techniques, Meteorol. Appl., 14, 389401, 2007.

Pascual, R.: Estudio de precipitaciones intensas en la comarca catalana del Maresme, Nota Técnica del Centro Meteorológico Territorial de Catalunya, 1, Instituto Nacional de Meteorología, 1999.

Peckham, D., Uman, M., and Wilcox Jr., C.: Lightning Phenomenology in the Tampa Bay Area, J. Geophys. Res., 89(D7), 11789-11805, 1984.

Petersen, W. A., Rutledge, S. A., and Orville, R. E.: Cloud-toground lightning observations from TOGA COARE: Selected results and lightning location algorithms, Mon. Weather Rev., 124,
602-620, 1996.

Pierce, C. E., Ebert, E., Seed, A. W., Sleigh, M., Collier, C. G., Fox, N. I., Donaldson, N., Wilson, J. W., Roberts, R., and Mueller, C. K.: The Nowcasting of Precipitation during Sydney 2000: An Appraisal of the QPF Algorithms, Weather Forecast., 19, 7-21, 2004.

Pineda, N. and Montanyà, J.: Lightning Detection in Spain: The Particular Case of Catalonia, in: Lightning: Principles, Instruments and Applications, edited by: Betz, H.-D., Schumann, U., and Laroche, P., Springer, 161-185, 2009.

Pineda, N., Rigo, T., Bech, J., and Soler, X.: Lightning and precipitation relationship in summer thunderstorms: Case studies in the North Western Mediterranean region, Atmos. Res., 85, 2, 159 170, 2007.

Rakov, V. A. and Uman, M. A.: Lightning: Physics and Effects, Cambridge University Press, Cambridge, UK, 687 pp., 2003.

Richard, P. and Lojou, J. Y.: Assessment of application of storm cell electrical activity monitoring to intense precipitation forecast, Proceedings of the 10th International Conference on Atmospheric Electricity, 10-14 June, Osaka, Japan, 284-287, 1996.

Rigo, T. and Llasat, M. C.: A methodology for the classification of convective structures using meteorological radar: Application to heavy rainfall events on the Mediterranean coast of the Iberian Peninsula, Nat. Hazards Earth Syst. Sci., 4, 59-68, doi:10.5194/nhess-4-59-2004, 2004.

Rigo, T., Bech, J., and Pineda, N.: Combining lightning and radar data to improve the nowcasting of summer thunderstorms, Proceedings of the International Symposium on Nowcasting and Very Short Range Forecasting (WSN05), Toulouse, France, 2005.

Rinehart, R. E. and Garvey, E. T.: Three-dimensional storm motion detection by conventional weather radar, Nature, 273, 287-289, 1978.

Riosalido, R.: Identificacion y caracterizacion automatica de celulas convectivas en volumenes radar, IV Simposio Nacional de Predicción, Memorial "Alfonso Ascaso", Madrid, 291-298, 1994.

Rivas Soriano, L., de Pablo, F., and Tomas, C.: Ten-year study of cloud-to-ground lightning activity in the Iberian Peninsula, J. Atmos. Terr. Phys., 67(16), 1632-1639, 2005.

Sairouni, A., Miró, J. R., Moré, J., Bech, J., and Rigo, T.: Impact of assimilation of observations into the MASS and MM5 models short-range forecast, EGU General Assembly, Wien, Österreich, 2007.

Seed, A. W.: A dynamic and spatial scaling approach to advection forecasting, J. Appl. Meteor., 42, 381-388, 2003.

Soul, K. M., Archibald, E. J., Hardaker, P. J., and Hounsell, A.: Using the GANDOLF system as a tool to aid the forecasting of lightning strikes, Meteorol. Appl., 9, 229-238, 2002.

Soula, S., Seity, Y., Feral, L., and Sauvageot, H.: Cloud-to-ground lightning activity in hail-bearing storms, J. Geophys. Res., 109, D02101, doi:10.1029/2003JD003669, 2004.

Soula, S.: Lightning and precipitation, in: Lightning: Principles, Instruments and Applications, edited by: Betz, H.-D., Schumann, U., and Laroche, P., Springer, 447-463, 2009.

Thielen, J., Bogner, K., Pappenberger, F., Kalas, M., del Medico, M., and de Roo, A.: Monthly-, medium-, and short-range flood warning: testing the limits of predictability, Meteorol. Appl., 16, 77-90, 2009. 
Trapero, L., Bech, J., Rigo, T., Pineda, N., and Forcadell, D.: Uncertainty of precipitation estimates in convective events by the Meteorological Service of Catalonia radar network, Atmos. Res., 93, 408-418, 2009.

Williams, E. R., Weber, M. E., and Orville, R. E.: The relationship between lightning type and convective state of thunderclouds, J. Geophys. Res., 94, 13213-13220, 1989.

Williams, E., Boldi, B., Matlin, A., and Weber, M.: The behavior of total lightning activity in severe Florida thunderstorms, Atmos. Res., 51, 245-265, 1999.

Williams, E. R.: The electrification of severe storms, edited by: Doswell III, C. A., Severe Convective Storms, Meteor. Mon., 28(50), Chapter 13, 527-561, 2001.

Wilson, J. W., Ebert, E. E., Saxen, T. R., Roberts, R. D., Mueller, C. K., Sleigh, M., Pierce, C. E., and Seed, A.: Sydney 2000 Forecast Demonstration Project: Convective Storm Nowcasting, Weather Forecast., 19, 131-150, 2004.
Wilson, N. L., Breed, D. W., Mueller, C. K., Saxen, T. R., and Demetriades, N. W. S.: The performance analysis of total lightning in NCAR's Auto-Nowcaster, Proceedings of the Second Conference on Meteorological Applications of Lightning Data, Atlanta, US, 2006.

$\mathrm{Xu}, \mathrm{G}$. and Chandrasekhar, V.: Radar storm motion estimation and beyond: a spectral algorithm and Radar observation based dynamic model, World Weather Research Programme Symposium on Nowcasting and Very Short Range Forecasting (WSN05), Toulouse, France, 2005.

Zipser, E. J. and Lutz, K. R.: The vertical profile of radar reflectivity of convective cells: a strong indicator of storm intensity and lightning probability?, Mon. Weather Rev., 122, 1751-1759, 1994. 